\title{
EL DEBER DE APRENDER A SER Y EL DEBER DE ENSEÑAR A SER EN EL DERECHO.
}

\author{
ViCTORIANO GALLEGO ARCE \\ Doctor en Derecho y Abogado \\ vgallegoa@gmail.com \\ Centro Universitario San Isidoro \\ Universidad Pablo de Olavide
}

\section{Resumen:}

El estudio centra su atención en las razones que justifican que el estudiante del Grado en Derecho adquiera una formación integral que le permita el ejercicio de una actividad profesional correcta desde una perspectiva técnica y ética.

A través de las competencias generales, comunes a todas las materias, se responde a la pregunta de qué es "saber ser" en el Derecho, como aquella capacidad que permitirá, desde la autonomía de la voluntad y de la libertad del profesional, cultivar unos principios y valores que les capacitará para adaptarse plenamente a la realidad social y profesional, para reaccionar con conocimiento, convicción y responsabilidad a los problemas que plantea la sociedad.

En esta línea se repasan los conceptos del respeto, la dignidad de la persona o la igualdad de oportunidades, como cimientos éticos que permiten erradicar injusticias, humillaciones o conductas corruptas.

Palabras clave: Competencias generales; Derecho; valores; respeto; dignidad, igualdad de oportunidades; docencia; trabajo en equipo.

\begin{abstract}
:
The research focuses it's attention on the reason that justify the student of Law dregee acquire an integral formation that allow the exercise of a correct profesional activity from a technical and ethical perspective.

Through a general competence, common in all subjects, the question of what is "knowing how to be" in the Law is answered, like that capacity that alow, from the autonomy of the will and professional freedom, to grow principles and values that will trains to adapt to the social and professional reality, to react with knowledge, conviction and responsibility to the problems posed by society.

In this sense the concepts of respect are reviewed, the dignity of the person or equal opportunities as ethical foundations that allow for the eradication of injustices humiliations or corrupt behaviors.
\end{abstract}

Key words: General skills; Law; values; respect; dignity, equal opportunities; teaching; teamwork. 


\section{Sumario:}

1. Introducción al tema de estudio. 2. "Aprender a ser": parte de la enseñanza universitaria a través de las competencias generales. 3. "Saber ser". La cuestión en el Derecho. 3.1. El concepto de respeto y el concepto de justica. La base de partida para progresar en la enseñanza de las competencias generales. 4. Conclusiones. Bibliografía.

\section{1.- Introducción al tema de estudio.}

Quedó escrito y publicado que:

“Todas las nociones que dábamos por sólidas, todos los valores de la vida civilizada, todo lo que mantenía la estabilidad de las relaciones internacionales, todo lo que mantenía la regularidad del régimen económico, en una palabra, todo lo que limitaba muy afortunadamente la incertidumbre del mañana, todo lo que daba a las naciones y a los individuos alguna confianza en el día de mañana, todo ello es hoy puesto en duda. He consultado todos los augurios (de todas las clases) que he podido encontrar y sólo he escuchado palabras muy vagas, profecías contradictorias, afirmaciones curiosamente endebles. Jamás la humanidad ha reunido tanto poder con tanto desasosiego, tanta inquietud y tantos juguetes, tantos conocimientos y tantas incertidumbres. La inquietud y la futilidad se reparten nuestros días.

A ustedes les corresponde ahora, queridos muchachos, abordar la existencia y, muy pronto, los negocios. Tarea no falta."

Si con estas palabras se pretende describir el escenario que hoy afrontan nuestros egresados al finalizar sus estudios, es porque esa descripción no es otra cosa que la representación de la vida misma. La vida es navegar por una única ruta, una única vez y con las cartas de navegación que nosotros mismos nos vamos dando y perfeccionando en el día a día.

La formación nos capacita para andar con mayor seguridad, para eliminar o disminuir ciertos (no todos) desasosiegos y preocupaciones, porque conocer nos proporciona referencias de distintas categorías (científicas, profesionales, sicológicas, culturales o morales) que nos orientan en el camino. Por el contrario, si caminamos sin referencias, es decir sin la "ayuda a la navegación" que nos proporciona la formación, la información o la experiencia, el resultado de nuestro destino será sólo el fruto del azar, de la ineficiencia, del riesgo y de la equivocación. En definitiva, navegaremos a merced de las corrientes y hasta que el barco aguante.

El estudiante ejerce el derecho y asume el deber de aprender a orientarse y a navegar en cualquier situación de la vida. Esto es, en las condiciones óptimas y placenteras, pero también en la oscuridad, con mar revuelto y, siempre, en la incertidumbre de las consecuencias de las decisiones continuas que tiene que adoptar.

Por otra parte, es de lógica palmaria que el cuadro de docentes que le ha formado asume la responsabilidad del acierto y de la oportunidad de determinadas decisiones que su discípulo adoptará. Consecuentemente, la capacidad de influencia del profesor determinará, de un modo u otro, los datos de navegación que introduzca su alumno o alumna. Es cierto que el profesional, cuando inicia su andadura, navega en absoluta 
libertad, pero no podrá desprenderse fácilmente de un modelo adoptado a través de las enseñanzas recibidas y, por ello, la velocidad y el rumbo que ha elegido -insisto- en libertad, la ruta escogida e incluso la seguridad propia y del resto de los navegantes, son, en cierto modo, producto de nuestra tarea docente. Todo ello será el fruto de un sistema de referencias que hemos contribuido a crear en él.

El sistema de referencias no nos asegura la certitud perpetua porque la incertidumbre y el error forman parte también de la vida; pero nos permite llegar a los fines de ésta, nos brinda la posibilidad de ganar en satisfacción personal y nos faculta para ser lo que uno o una es (en la profesión o fuera de ella). Por ello, contar con un adecuado sistema de referencias es beneficioso para todos los individuos. Y lo que es beneficioso a nivel individual se proyecta positivamente al cuerpo social.

La sociedad no sólo necesita buenos profesionales, sino también buenas personas y buenos ciudadanos que lleven una "vida buena" (en el sentido aristotélico), es decir, mujeres y hombres que cultiven la excelencia de manera integral, porque la fortaleza y el progreso de la sociedad tiene que producirse de manera "íntegra", 1 dicho en un doble sentido: mediante la confluencia coordinada de todo tipo de conocimientos, actividades y profesiones y a través de la integridad de cuantos la forman. Una unidad importantísima en la que no cabe prescindir ni ignorar a ninguna de sus partes.

De manera que los estudiantes universitarios deben alcanzar unos resultados de aprendizaje y haber adquirido unas capacidades y habilidades, que les proporcionen aptitud para el desempeño de la profesión que ellos libremente han elegido. E igualmente importantes son todas aquellas destrezas $\mathrm{y}$ habilidades personales, interpersonales o sociales, que habilitan al ser humano a aprender y aprehender el sistema de referencias que necesita articular para vivir (convivir) en el mundo. Esto es, la actitud para andar, junto a los demás, en los momentos de oscuridad y de niebla.

En este sentido, con aquellas destrezas y habilidades bien afianzadas, el profesional o el estudiante, podrá prever cambios (los que puedan preverse), planificar su seguridad e incluso, en determinados casos, modificar el propio sistema de referencias. Y así nunca le afectará la falta de estabilidad, porque dispondrá de recursos suficientes para adaptarse a un mundo siempre cambiante.

Esa es la gran labor de la docencia: facilitar al estudiante los recursos, medios y procedimientos con los que pueda construir y mejorar su propio conocimiento.

Siendo el error un compañero inseparable del actuar humano, al menos, hay que intentar no hacer las cosas mal. Decimos que una cosa "está mal" cuando contiene un error, es decir, cuando no es correcta desde el punto de vista científico o técnico; pero también está mal cuando esa cosa se aparta de la rectitud exigible. En el primero de los casos se trata de un error intelectual y, en el segundo, estamos ante un error moral ${ }^{2}$. Aún así, no es menos cierto que, en uno u otro caso, alguien podrá sufrir (seguramente sufrirá) los efectos y consecuencias del error que, en mayor o menor grado, conducirán a la producción de daños o perjuicios, a situaciones injustas, conflictos o controversias que afectan directamente a la convivencia. En suma, la falta de conocimientos genera error,

\footnotetext{
${ }^{1}$ Según el Diccionario de la Real Academia, integridad se define como "la cualidad de íntegro" o "la pureza de las vírgenes". Etimológicamente procede del latín "integritas" como "lo no tocado", ("in" -no- y "tangere" -tocar-) y designa lo recto, honesto, sano, valioso y puro.

${ }^{2}$ Vid. Schulz, K. 2015. En defensa del error. Madrid. Siruela. Pág. 24.
} 
pero la falta de convicciones morales puede degradar o incluso dejar huera una formidable formación técnica o intelectual.

Frente a las voces que afirman que el ser humano moderno ha dejado de creer en lo que no comprende y ha reducido el mundo de sus esperanzas a las máquinas, las teorías económicas, las organizaciones o las religiones, entre otras, (es decir, en cosas que siempre están fuera de él mismo ${ }^{3}$ ) nuestros alumnos y alumnas deben creer también en ellos mismos, porque ellos tomarán las decisiones que compondrán el mundo del mañana. En definitiva, lo que pase mañana será, ni más ni menos, que el resultado de lo que hagamos, o lo que es lo mismo, el fruto de nuestras decisiones y de nuestras acciones de hoy.

Es cierto que estamos asistiendo a un gran cambio tecnológico y social que trasciende también al ámbito educativo. Es cierto que este cambio es único, que nunca antes la sociedad había experimentado algo así, pero tampoco significa que todo lo anterior no sirva. En buena lid, habrá cosas que tienen que perdurar intactas, otras se adaptarán a la nueva situación y otras desaparecerán. Es muy difícil ser conscientes del cambio y de la evolución de los hechos y acontecimientos que experimentamos cada día, porque pocas personas gozan de una visión lejana tan aguzada como para ver las consecuencias finales de lo que hoy vivimos. Así ha sido a lo largo de nuestra historia.

Lo realmente significativo es que seamos capaces de deslindar las novedades que el mundo actual puede darnos de las entidades de siempre que puede quitarnos. Así las cosas, la revolución tecnológica nos ha permitido en poco tiempo la comunicación global y en red (en la que todos comunican con todos); nos proporciona un acceso inmediato a la información, y al mismo tiempo nos obliga a ser capaz de discernir la buena información de la mala información (ente otros, el fenómeno de la postverdad). Todo ello unido a que, en muchas ocasiones, surgen unos planteamientos sociales equivocados en los que parece que "moral" está directamente relacionada con la religión y por tanto, hablar de moral es situarse extramuros del Estado aconfesional.

En resumen, asistimos a un mundo en el que la persona se relaciona más con las máquinas que con el resto de las personas; donde la tecnología y la economía mandan y establecen las pautas, mientras los valores se "desvalorizan" hasta el punto de que parece que cuanto más avanza la ciencia, más retrocede la moral.

Ese es el escenario que vivimos y los docentes universitarios tenemos el deber de instruir a los capitanes del barco que navegarán en estas aguas. Es evidente que sólo intervenimos en la faceta profesional de la persona, pero es indudable que de nuestros resultados, como profesor o profesora, dependerá el tipo de barco que nuestro egresado sea capaz de dirigir y cómo lo dirigirá.

En definitiva, es capitán de la nave de su vida porque hemos enseñado a esa persona a ser capitán. Podemos auto engañarnos, consolarnos y repartir culpas con el resto de la sociedad, con los niveles de enseñanza anteriores o incluso con la familia, pero lo cierto es que la Universidad es la que, en muchas ocasiones, afianza que ese hombre o mujer, que se pone al frente del barco, "sabe ser" capitán. Este es el punto en el que fijamos el foco del presente estudio: la denominada formación integral que debe impartirse y vislumbrarse en cualquier asignatura del Grado en Derecho.

\section{2.- "Aprender a ser": parte de la enseñanza universitaria a través de las competencias generales.}

\footnotetext{
${ }^{3}$ Navarrete, R. 1993. El aprendizaje de la serenidad.6 ${ }^{\text {Ed }}$. Madrid. San Pablo. pág.217.
} 
Es comúnmente conocido que, coincidiendo con el cambio de siglo, brotaron importantes ideas e iniciativas que concurren (en lo que al tema que proponemos se refiere) en la necesidad de estructurar la diversidad de titulaciones y de perfiles profesionales, sobre un basamento común e integrador, que aporte a la sociedad el resultado final de un proceso educativo que se corresponda plenamente con las necesidades que la propia evolución social demanda.

Para este propósito extraemos del capítulo cuarto del conocido "informe Delors" los denominados "cuatro pilares de la educación" necesarios para la realización íntegra y plena de la persona. Estos cuatro aprendizajes fundamentales son descritos como: aprender a conocer, es decir, adquirir los instrumentos de la comprensión, manejar los instrumentos que le permitan conocer, comprender, descubrir la ciencia y comunicarse (aprender a aprender para poder aprovechar las posibilidades que ofrece la educación a lo largo de la vida -dice el autor-); aprender a hacer, directamente relacionada con el anterior, permite poner en marcha los conocimientos adquiridos; aprender a vivir juntos, para participar y cooperar con los demás en todas las actividades humanas con solución pacifica de los conflictos (en palabras de Delors, desarrollar la comprensión del otro y la percepción de las formas de interdependencia -realizar proyectos comunes y prepararse para tratar los conflictos- respetando los valores de pluralismo, comprensión mutua y paz); por último, aprender a ser, como proceso fundamental que recopila aspectos de los tres anteriores y que permite la realización de un proyecto personal en libertad, tomar decisiones con autonomía, fortalecer los valores personales y el desarrollo de la personalidad.

Unos años más tarde, en el año 2000, con ocasión del proyecto Bolonia, surge la necesidad de armonizar las estructuras de los programas educativos universitarios (sin perder de vista la diversidad y la autonomía universitarias), de manera que se articuló un sistema de titulaciones fácilmente reconocibles y comparables entre los Estados. Nace así el proyecto Tuning ("Tuning Educational Structures in Europe") con el propósito de "afinar" (en el sentido musical) o, si se quiere, "sintonizar" las estructuras educativas de Europa en el ámbito universitario a través de un lenguaje común. La metodología que persigue el proyecto Tuning se basa, entre otros aspectos, en entender el concepto de competencia como la combinación de conocimientos, comprensión, destrezas, habilidades y actitudes adquiridas, separando entre competencias específicas y competencias genéricas de "conocer y comprender" -conocimiento teórico de un campo académico-, "saber cómo actuar" -la aplicación práctica y operativa del conocimiento en situaciones determinadas- y "saber cómo ser" -disponer de unos valores como parte integrante de la forma de percibir a los otros y vivir en un contexto social-. Se centra, por tanto, en las competencias específicas de las áreas (determinadas y concretas de cada campo de estudio) y en las genéricas (comunes para cualquier curso).

Ambos estudios coinciden en que la Universidad debe tender hacia una formación técnica y humanista; es decir, una formación integral, que cultive conocimientos,

\footnotetext{
${ }^{4}$ Jacques Delors fue el Presidente de la de la Comisión Internacional sobre la Educación para el Siglo XXI, (conocida como "Comisión Delors" o "Comisión") convocada por Director General de la Organización de las Naciones Unidas para la Educación, la Ciencia y la Cultura (UNESCO), D. Federico Mayor Zaragoza con el objetivo de reflexionar sobre la educación y el aprendizaje en el siglo que estaba a punto de comenzar. Las conclusiones de dicha Comisión se recogerían en un informe para la UNESCO. Dicho informe fue publicado con formato de libro en 1996 con el título "La educación encierra un tesoro" Madrid, España: Santillana/UNESCO.
} 
habilidades en su plena dimensión técnica, pero que también se procure el cultivo de valores para la mejor comprensión de la realidad. Dicho de otra manera, aprender a navegar en la vida con la conciencia de lo que se debe ser y de lo que se debe hacer homo aeticus-.

El legislador andaluz también quiso plasmar esta idea, aunque sea sólo en la exposición de motivos de la ya derogada Ley de Universidad de Andalucía, cuando señaló que " $L a$ generación del conocimiento debe vincularse asimismo a la configuración de una inteligencia social que implique una nueva ética, una comprensión distinta de las relaciones sociales. En particular, deben establecerse las bases que permitan a las Universidades ser capaces de impulsar y de comprometerse con la educación integral de los jóvenes para que sean actores de la gran transformación cívica que requiere alcanzar un mundo más justo y equilibrado" 5 .

Tampoco se quiere transmitir la impresión de que estas apreciaciones nacieron con el siglo XXI, porque mucho antes de elaborarse el informe Delors, concretamente en 1972, se publicó el estudio conocido como Informe Faure 6 que, precisamente, se detenía en el "aprender a ser" como un aspecto muy importante para completar la formación integral del universitario o universitaria, con el objetivo de que "pueda afirmar sus responsabilidades cívicas y sociales y reaccionar ante las contradicciones y las injusticias".

Otro aspecto a tener en cuenta es que los planes de estudio de las distintas titulaciones (el Derecho no es una excepción) se estructuran atendiendo a una especialización sectorial por ramas que, en no pocas ocasiones, provocan una fuerza en sentido contrario a la visión integral de la formación que aquí que se refiere. Esto origina que la actuación docente se focalice en ese sector que especializa al profesor o profesora, de tal manera que el docente conoce, rozando la perfección, las más íntimas características de la gota de agua que estudia afanosamente (y que ha estudiado durante años), pero descuida mirar, de vez en cuando, al océano en el que se incluye y del que forma parte dicha gota de agua, y, en consecuencia, también descuida explicar y enseñar cómo centrarse en esa gota después de haber sobrevolado (y sin perder de vista) la masa de agua de la que forma parte (conocimiento sistémico).

Velar por esta formación integral no es un valor añadido del docente, sino que es una exigencia que se concreta en esas competencias generales que, junto a las específicas, figuran también como un deber de resultado de aprendizaje. Además, atender a estas cuestiones generales, aúna no sólo esa visión general del Derecho o disciplina que tratemos, sino que favorece la actuación coordinada del equipo docente. Aspecto éste que no deberá descuidarse, pues si se pretende que la Universidad "produzca" profesionales de excelencia, no será por la actuación de un único profesor o de unos cuantos del conjunto de docentes que imparten las distintas materias -lo contrario sería admitir la nula o ineficaz intervención del resto-, sino por la confluencia de los

5 Exposición de motivos de la Ley 15/2003, de 22 de diciembre, Andaluza de Universidades, hoy derogada por el Decreto Legislativo 1/2013, de 8 de enero, por el que se aprueba el Texto Refundido de la Ley Andaluza de Universidades.

${ }^{6}$ En 1972, René Maheu, director general de la UNESCO, encomendó a Edgar Faure, Presidente de la Comisión Internacional para el Desarrollo de la Educación establecida por la UNESCO, ex Presidente del Consejo y ex Ministro de Educación de Francia, un informe sobre el Desarrollo de la Educación a nivel mundial. Faure, E. y otros. (versión española de Paredes de Castro, C.)1973. Aprender a ser. La educación del futuro. Madrid. Alianza editorial. 
esfuerzos que todo el grupo. Y todos sabemos que un conjunto humano que persigue un fin común, alcanzará más y mejores objetivos si actúa de manera coordinada y liderada, esto es, si tiene un sentimiento de equipo.

Quiere decirse que el docente universitario no sólo crea unidad con los que conforman su departamento o con todos aquellos con los que comparte especialización (eso sólo tiene sentido para la tarea investigadora), sino que ha de ser consciente de que el resultado final formativo es el sumatorio de todas las ramas o especialidades que trabajan en la consecución de un objetivo común y de interés general.

En la existencia de esa armonía y en el estrecho contacto que debe existir entre todos los miembros del equipo docente, se explica, a mi juicio, gran parte del significado de lo que algunos documentos recogen como "formación integral". Porque sin esa idea de conjunto armónico en la que se debe estructurar el equipo docente, sólo queda "que cada uno haga la guerra por su cuenta". En definitiva, el escenario propicio para la aspirada formación integral será aquel en el que esa "integridad de la enseñanza" organice eficientemente el "enseñar a ser"'.

\section{3.- "Saber ser". La cuestión en el Derecho.}

¿En qué consiste el "saber ser" del Derecho? En ciertas profesiones puede que sea muy fácil delimitar en qué consiste el "saber ser" (por ejemplo, el caso del médico), pero cuando se forman juristas, ¿en qué profesión de referencia estamos pensando?; ¿en un abogado?, ¿en un juez?, ¿en un notario?, ¿en un funcionario?, ¿en un asesor jurídico de empresa? Tal vez ¿en un asesor jurídico de la Administración Pública?, ¿en un inspector?

Todos estos profesionales pasan por las facultades de Derecho, pero no todos están sometidos a la misma deontología, a los mismos códigos de conducta, porque no todos están regidos por los mismos valores éticos en el ejercicio de sus cometidos específicos y en los servicios que prestan. Sin embargo, todos contienen un núcleo común de principios y valores principales o primarios que proporciona su formación jurídica.

En principio, se trata de un cuerpo de valores que son llevados a la práctica en la resolución de los conflictos diarios y generales de la vida, que otorgan a la actividad cotidiana del egresado un plus de tranquilidad, de seguridad, de buen hacer, de justicia y de paz que, independientemente del puesto que vaya a ocupar o actividad que pueda desempeñar, se convierta en un ser imprescindible para la ciudadanía a la que sirve. En definitiva, una persona con valores se convierte en el faro y en la ayuda a la navegación que necesita la sociedad para orientarse en cualquier situación por desfavorable que sea. Es una referencia para navegar en los días de niebla que tiene la vida y en las horas de oscuridad que tiene el día, con el mar de la vida agitado o en calma.

Para ello, el estudiante tiene que poseer la capacidad de situar el problema que se le plantea, no sólo desde el punto de vista jurídico, sino contextualizarlo de forma histórica, filosófica, social y política (o, en algunos casos, despolitizada). En definitiva, hemos de lograr un profesional transformador de la sociedad.

En consecuencia, las habilidades y aptitudes que ha de lograr el jurista van mucho más allá del mero aprendizaje de unos contenidos normativos, doctrinales y jurisprudenciales reforzados con la realización de unas prácticas obligatorias. Algo obvio y que es conveniente decir, es que la institución encargada de alcanzar la excelencia del jurista, en todos sus aspectos, es la Universidad, por lo que no debemos declinar en otros -empresa, familia, enseñanza secundaria o en la sociedad en general- 
la formación en valores vinculadas con la actividad profesional que va a desarrollar el futuro profesional.

Por consiguiente, si pensamos en un Derecho transformador de la sociedad, basado en valores, es preciso trazar el grado moral que se pretende impartir y el catálogo de valores sobre los que se necesita incidir para dar sentido lógico a aquellas competencias generales. Pero, ¿de qué tipo de moral estamos hablando? Se trata de una moral que conduce a la rectitud de los actos. Y por tanto, es una moral que se aleja de valores encorsetados, propia de una moral religiosa. Por eso se utiliza la construcción de un andamiaje ético que resista el paso del tiempo y que a la vez no se resista al paso del tiempo. Por lo que esta paradoja podrá entenderse cuando el sistema ético contiene en sí mismo un mecanismo necesario para que el cambio moral se adapte a la evolución social.

En palabras de la profesora Adela Cortina, "por «moral» se ha entendido y entiende fundamentalmente la realización de la vida buena, de la vida feliz, el ajustamiento a normas específicamente humanas, e, incluso en nuestro tiempo, aptitud para la solución pacífica de conflictos, sea en grupos reducidos, a nivel nacional o en el ámbito de la humanidad"7.

Cuando la enseñanza se limitaba al aprendizaje de un manual preestablecido y la moral a la preservación de una serie de conductas directamente vinculadas con la religión dominante, todo estaba perfectamente uniformado. La revolución tecnológica, la digitalización y la globalización, sin embargo, nos han transportado a un mundo de opciones que está presidida por el omnipresente "menú" o el "me gusta" -entre otroscon el que parece que podemos sortear o engañar la difícil andadura que presentaba aquella opción única.

Incluso la verdad, que se antojaba única e irremplazable, puede ser desplazada por una narrativa que afecta a las emociones (a través del retuits, voto, comparto o me gusta). Parece que ya no interesa si algo es cierto o no. Los hechos, base de la construcción de la decisión, no parecen tener importancia, porque lo importante son los impactos que la difusión del acontecimiento ha tenido en las redes sociales y, consecuentemente, cómo ha afectado a la emoción de esa parte del público que se ha manifestado, porque puede haber un público mayor que, por otras razones -a veces la corrección política- no manifiesta sus sentimientos al respecto.

No cabe duda de que ese invento que ahora se llama ahora "posverdad" (que no es más que el nombre moderno con el que se designa a la mentira de toda la vida), afecta al buen régimen del Derecho; porque conduce a soluciones alejadas de la racionalidad y razonabilidad. Porque crea injusticia, inequidad y frustración debido a que a nadie le gusta que le mientan o que le manipulen; porque no es bueno convertir el conflicto en espectáculo, promover soluciones que exigen cambiar las reglas del juego después de celebrada la partida o pretender alcanzar soluciones mediante el empleo de los medios de comunicación social a sabiendas que los juzgados y tribunales no lo han otorgado, porque pueden otorgarlas; y porque no es bueno que se transmita a la sociedad la falsa idea de que el Derecho puede mimetizarse cuando no nos conviene aplicarlo o puede estirarse para que se adapte acorde con la moda, con lo políticamente correcto o a las emociones expresadas por unos cuantos en las redes sociales.

\footnotetext{
${ }^{7}$ Cortina. A. 2000. Ética mínima. $6^{\circ}$ ed. Madrid. Tecnos. Pág. 57. Disponible también en https://es.slideshare.net/JennyJimenez1/cortina-adela-eticaminima-16493201.
} 
Una cosa es la sana y no siempre fácil interpretación y argumentación del Derecho y, otra bien distinta, es creer que puede ser un circo en el que las fantasías se presentan como reales, las palomas salen de las chisteras o cualquier persona puede meter la cabeza en la boca del león. Todo eso no es más que un tremendo engaño alejado de la razonabilidad y racionalidad que debe presidir la resolución de un conflicto para que no se cierre en falso.

Los valores son "valorados" porque "cuesta" tenerlos, porque exige a quien los posee un gran esfuerzo para cultivarlos y mantenerlos en continuo crecimiento. Es el valor por sí mismo y su presencia en el ser humano, lo que engrandece a la persona y a sus relaciones con los demás. Si se respeta a la persona, si se piensa desde la paz, desde la justicia, desde la igualdad de oportunidades o desde la responsabilidad -entre otros valores- es difícil que exista el conflicto o que, surgiendo, no se resuelva con rapidez. La moral, como escenario en el brotan los valores, se convierte en el espacio en el que reina la libertad. Mientras que el Derecho trata de evitar la humillación y la agresión mediante la coacción, pero no evita las conductas humillantes y agresivas cuando quienes las llevan a cabo no transgreden la "delgada línea" de la ley. Sin embargo, el respeto sí evita conductas humillantes.

No hay atajos para la rectitud de nuestra actuación. Aquí no existe un despliegue de opciones en el menú, no existen trucos, malabarismos, ni 'preguntar a "Don Google". En el mundo real, la calidad de los resultados obtenidos es directamente proporcional al cuidado que hayamos invertido en el cultivo de nuestros valores. $\mathrm{O}$ se es honrado o no se es. O se está contra la corrupción o se está a favor. Es indudable que esto hay que enseñarlo. Esto tiene que estar presente en las relaciones del profesor-alumno en todos y cada uno de los actos docentes y en todos los comportamientos, dándoles sentido en lo racional y en lo emocional.

El profesor Pérez Lledó critica que no conoce a nadie que se dedique a la Universidad movido principalmente por el deseo de docencia ${ }^{8}$, y que, en el caso de ser hallado, éste sería considerado como un "bicho raro" o, peor aún, como un investigador perezoso e incompetente que se ampara en la docencia para eludir la tarea investigadora ${ }^{9}$. A pesar que no preconiza que sea a la inversa, el profesor tampoco considera adecuado que la docencia sea "la pariente pobre" de las tareas del profesor universitario.

Así las cosas, investigación y docencia deben constituir las actividades del profesor o profesora en una aproximación al aurea mediocritas (dorado término medio) de Aristóteles, es decir, con adecuada ponderación y sin que una u otra esté descompensada.

\section{1.-El concepto de respeto y el concepto de justica. La base de partida para progresar en la enseñanza de las competencias generales.}

Dentro de las competencias generales que deben ser adquiridas por el estudiante ante las demandas del mundo de hoy, encontramos algunas que, de modo directo, se encuadran plenamente en la necesidad de "aprender a ser" (por ejemplo, capacidad de evitación y la resolución pacífica de problemas; adquirir valores y principios éticos para la convivencia social; reconocimiento a la diversidad y la multiculturalidad o la

\footnotetext{
${ }^{8}$ Pérez Lledó. J. A. 2007. "Teoría y práctica en la enseñanza del Derecho". Academia: revista sobre enseñanza del derecho de Buenos Aires, Año 5, Número 9. pág. 89.

${ }^{9}$ Humildemente he de decir que este autor sí que centra su actuación y preocupación en la docencia, no se considera perezoso, pero sí un investigador más que mediocre, aunque no es el ese el motivo por el que le apasione la docencia.
} 
sensibilidad hacia temas de la realidad social, económica y medioambiental). Mientras que otras, como es la adquisición de la capacidad de trabajar en equipo, son resultados perfectamente verificables de lo que el alumno es "capaz de hacer" al término de su proceso formativo, lo cual difícilmente podrá alcanzarse si la persona no ha consolidado los principios y valores que permiten la buena convivencia. Sencillamente, trabajar en equipo supone trabajar "con las personas" y, una base sólida de valores y principios, se convierte en el más completo y amplio "manual de instrucciones y procedimientos" que el futuro profesional tienen que conocer y mantener actualizado.

Especialmente en disciplinas como el Derecho, que hincan su razón de ser en el servicio directo a la persona, por la persona y para la persona, individualmente considerada o en los grupos de los que forma parte.

Más que centrarnos en la adquisición de las competencias enumeradas ut supra, la clave está en alcanzar con solidez la base sobre la que deben levantarse sus resultados. Esto es, la interiorización de conceptos superiores, como el respeto o el criterio de justicia, que son bases ineludibles para avanzar en otros valores, igualmente importantes, como son la honradez, la paz, la responsabilidad o la honestidad, entre otros.

Sirva un ejemplo como base de lo que se quiere exponer: en la Madrugada de la Semana Santa sevillana de 2017, se produjeron unos incidentes lamentables de gamberrismo, consistentes en carreras y avalanchas de público que, además de un determinado número de heridos de diversa consideración, sembró el caos, la inseguridad y el miedo donde todo el mundo deseaba disfrutar de la celebración religiosa o del simple descanso.

Con motivo de aquellos sucesos planteé a mis alumnos la pregunta de por qué creían ellos que se habían producido aquellos acontecimientos de la madrugada y si estaban de acuerdo con la repercusión que habían tenido en los medios de comunicación social. La respuesta fue rápida, unánime y sencilla: eran hechos graves, estaba justificado el tratamiento mediático que se le había otorgado y el origen de los mismos era una total falta de respeto a los demás.

La complicación surgió después: cuando se trató de precisar qué debemos denominar "respeto", en qué consiste "respetar" y cuando se llega al "no respeto".

Reorganizando ideas básicas sobre el término, descubrimos, desde el inicio, que no sólo no se trata de una noción de cortesía, educación, urbanidad o esos aspectos que el estudiante debe traer sabido de casa, sino que, para el estudiante de Derecho, se convierte en la argamasa con la que construye la fábrica jurídica personal en la que se desarrollará su vida profesional. Recordemos que en el mito de Prometeo, Zeus temió que sucumbiera toda nuestra raza, y envió a Hermes para que trajera a los hombres el respeto y la justicia con el fin de que hubiera orden en las ciudades. De esta forma, el sofista Protágoras, pretendió explicar la importancia y la justificación de la ley como el origen de la cultura. No obstante, desde la perspectiva kantiana, respeto es también la no instrumentalización del otro para conseguir mis fines, sino la percepción clara de que todas y cada una de las personas con las que nos relacionamos son fines en sí mismas y no medios para los fines de otros. ${ }^{10}$

En definitiva la auténtica igualdad del ser humano, que conecta el respeto con la dignidad, que es donde somos auténticamente iguales, nos conduce a tratar al otro con

${ }^{10}$ Metafísica de las costumbres. Doctrina de la virtud, I, $§ 25$. 
absoluto miramiento, atención y deferencia, porque cualquier desconsideración hacia la dignidad de la persona genera la humillación, el agravio y la ignominia en sus distintos grados.

De este modo resulta esencial interiorizar, aprender y aprehender la consideración de lo humano que, bajo ningún concepto, puede limitarse a la simple cortesía, al buen trato o a la preservación de las costumbres del lugar, como tampoco a la simple tolerancia de las conductas, porque respetar a la persona no impide manifestar la intolerancia ante las conductas que ésta despliega. Esto es, que el respeto es la suprema intención de no ofender, de no manipular y de no instrumentalizar a nuestros semejantes. Y como no es un valor reservado a unos pocos o que sólo unos cuantos debamos cultivar, su característica esencial y suprema es la plena reciprocidad.

En las aulas y en los textos se muestra con frecuencia un concepto de respeto extraído de la vida cotidiana y que, aunque a veces resulta pedagógicamente útil, en otras ocasiones, su descontextualización conduce al error, por ejemplo cuando se trata el concepto de respeto como miedo o recelo, por aquello de "que el miedo guarda la viña".

Es cierto que el respeto a las normas y a las personas puede ser generado más por temor a la reacción coactiva de la norma sobre el infractor que por convicción de la necesidad de su comportamiento. Y en este mismo sentido, el jurista que se forma en las aulas es conocedor de la herramienta de fuerza que se contiene en el Derecho, reservada para cuando las "cosas se tuercen", pero no para la contribución a una sociedad en convivencia pacífica, que estará regida por otro refrán español: "donde hay amor, no hay temor" (donde hay respeto no existe arbitrariedad, desprecio, humillación o violación de los derechos).

En consecuencia, el respeto y el miedo son cosas muy distintas y no debe ser utilizado en las aulas de la universidad como sinónimo, ya que, adquirida la madurez necesaria para ingresar en estas magnas clases, ya se ha entendido que aquello que se aprendió a respetar en la niñez por simple temor, se ha consolidado digno de respeto por convencimiento racional $^{11}$.

En realidad de poco sirve buscar excusas y justificaciones del por qué no se ha avanzado en la interiorización del concepto de respeto (a pesar de las ventajas que ello produce), sino que la clave está en no obviar la gran dificultad que supone actuar persuadidos por el deber de tratar al resto de nuestros semejantes desde la convicción de una absoluta igualdad en dignidad $\mathrm{y}$, al mismo tiempo, desde las diferencias que hacen único e irrepetible a cada ser humano. Por una parte, se trata de una lección severa y de tremendo rigor, porque el sentido común nos dice que debemos tratarlo como a uno mismo y, por otra parte, porque debemos ser conscientes, asumir y respetar que existen diferencias entre todos los seres humanos ${ }^{12}$.

${ }^{11}$ El objetivo de la educación es aprender a respetar por alegre interés vital lo que comenzamos respetando por una u otra forma de temor. Pero no podemos abolir el miedo del comienzo del aprendizaje y es ese miedo primero, controlado por la autoridad paternal, el que nos vacunará para que no tengamos más tarde que estrellarnos contra terrores frente a los que no estaremos preparados. Sabater, F. 1997. El valor de educar. Barcelona. Ariel. (Pág. 31).

${ }^{12}$ Sennett. R. 2003. El respeto. Sobre la dignidad del hombre en un mundo de desigualdad. Barcelona. Anagrama. Pág. 56. 
La no remoción de todos estos obstáculos, nos lleva a rodear el respeto sin atrevernos a practicarlo en toda su intensidad. Buscamos sucedáneos, como la tolerancia, que nos ayuden a suplir la esencia por la apariencia. Y así encontramos a adultos autodenominados "tolerantes" que sólo toleran "lo que les gusta" a ellos y que aquel o aquella que no comparte sus gustos, ideas $u$ opiniones, se arriesgan a recibir calificativos negativos.

En tal caso, como explicaba Bobbio, nos llegamos a olvidar de que la razón moral de la tolerancia es el respeto. La tolerancia no reposa sobre la renuncia a la propia verdad, o sobre la indiferencia por cualquier forma de verdad, sino que esta debe entenderse como la conciliación entre la situación de propia verdad, por encima de cualquier otra cosa, y el respeto o la benevolencia hacia el otro ${ }^{13}$.

Mientras que la tolerancia se aplica a las conductas, nunca a las personas, el respeto, en cambio, se aplica a las personas, nunca a las cosas, a las conductas o las opiniones. No se respeta a la altura, a la montaña o a las tesis de un partido político, por ejemplo. No obstante, se tolera o no la altura, en función del vértigo que se sufra; se toleran o no las circunstancias de vida en montaña, y se tolera o no, el ideario de un grupo político (porque no deben tolerarse tesis terroristas, de supremacía, o contrarias a los Derechos Humanos, por ejemplo). En cambio, existe un deber de respeto a todas las personas, les guste o no les guste la altura, la montaña o los extremismos políticos.

En este sentido, se pronuncia el profesor Sabater cuando explica que vivir en una sociedad plural impone asumir que lo absolutamente respetable son las personas, no sus opiniones, y que el derecho a la propia opinión consiste en que ésta sea escuchada y discutida, no en que se la vea pasar sin tocarla como si de una vaca sagrada se tratase ${ }^{14}$.

Además del respeto, el jurista que formamos debe ser una persona imbuida de un sentimiento de justicia y de paz. Esa es la razón de ser del Derecho: perseguir la justicia y la paz, poner orden en el caos y que el interés general, el bien común y la defensa de los derechos de las personas, justifiquen todos y cada uno de sus actos. En cambio, utilizar el Derecho para lograr cotas de poder, beneficios económicos o reconocimiento público, podrá ser más o menos lícito, pero no es ético. El jurista entonces se convierte en un depredador que vive la vida desde la economía pero no desde el Derecho.

Parece que si les decimos a nuestros estudiantes que siguiendo todos estos principios y valores, viviendo la vida de esta manera, se convertirán en referencia moral para los demás, vivirán con la satisfacción del deber cumplido, influirán en los demás de acuerdo con los tiempos que les tocará vivir, se sentirán orgullos de una vida de servicio a los demás, pero no serán ricos, puede que algunos (tal vez todos) se levanten de sus asientos y se vayan.

Entonces, la pregunta es obvia: ¿qué tipo de juristas quiere formar la Universidad?

El jurista, al igual que el soldado, ha de ser formado para la paz. El militar hace la guerra para lograr la paz. La paz no vista en sentido negativo (ausencia de conflictos o espacio entre los mismos) sino paz en sentido positivo tal y como nos la enseñó Galtung. La paz es el transcurrir de la vida con seguridad y con tranquilidad. La paz es la certeza de que, esta tarde, cada uno de nosotros y cada uno de nuestros seres queridos, verá el atardecer y, de la misma manera y sin solución de continuidad, mañana

\footnotetext{
${ }^{13}$ Bobbio. N. 1991. El tiempo de los derechos. Sistema. Madrid. Pág. 248-249.

${ }^{14}$ Op. Cit. Pág. 60.
} 
disfrutará del amanecer. Mientras que al otro lado de la paz, existen quienes por los motivos más nimios prefieren dar muerte a sus semejantes, a los que considera adversarios, antes que renunciar a sus razones.

El guerrero no inventó la guerra. Fue la guerra, el germen de la violencia que todos llevamos dentro, quien creó al guerrero. El soldado es un servidor público que está dispuesto a servir a los demás hasta el último sacrificio, que es la entrega de su propia vida. Es por ello que la sociedad pone en las manos del soldado unas herramientas de trabajo que son letales y exige a sus Fuerzas Armadas que manejen las armas con destreza, con precisión, que conozcan la doctrina y los procedimientos que se emplean en el combate pero, a la vez, les obliga a que actúen con sujeción plena a unos principios y valores de servicio a los demás y de entrega a los ciudadanos, que contiene respeto, responsabilidad, sacrificio, constancia, con subordinación a la Ley, al Derecho y a los derechos de los demás.

Salvando las distancias, de la misma forma, el jurista es formado y tiene que ser diestro en el manejo de las normas, en los procedimientos, en la argumentación, en la oratoria y en el empleo del Derecho. Recordemos que "contencioso", tiene la misma raíz que contienda, que en el lenguaje forense se habla de "armas procesales", de "igualdad de armas", de la "constroversia entre las partes" o de la "táctica y la estrategia" procesal.

En la comparación de ambas situaciones, las dos presentan ciertas coincidencias, desde la clara diferencia de que en el primer supuesto nos encontramos en una situación de extrema violencia y la segunda es un intento de garantizar el Derecho, sin violencia (claro está).

No obstante y siguiendo con el símil, la pregunta comprometida es: ¿la sociedad quiere entregar estas "armas procesales" a alguien que sabe manejarlas, a quien demuestra un gran adiestramiento técnico y táctico y que ha sido evaluado sobre los principios y valores que deben presidir su actuación, o, por el contrario, prefiere prescindir de esto último?

Cuando la sociedad o las personas buscan únicamente satisfacer sus necesidades (que son infinitas, porque eso nos enseña la economía) y carecen de los bienes, los recursos o los argumentos necesarios para ello, acaba acudiendo a los bienes y derechos de otros. Eso y no otra cosa es lo que motiva la guerra. La guerra entre las personas y la guerra entre los pueblos ${ }^{15}$. Por lo que un jurista, cuyo quehacer diario está presidido por un pensamiento económico y no por un pensamiento justo, vive de acuerdo con el homo hominis lupus o en "el pez grande se come al pequeño" y, por tanto, vivirá siempre "en tiempo de guerra" y no tendrá aprehendidos los principios de igualdad de oportunidades, el de respeto y el de dignidad. En definitiva, su concepto de dignidad estará huero.

Por el contrario, el jurista con pensamiento justo (como aquel soldado calderoniano), acude al combate con la finalidad de lograr la paz o, lo que es lo mismo, para lograr el pacto justo (pax y pactum derivan de la misma raíz) ${ }^{16}$. Este jurista llega al conflicto para poner fin al caos y para que "el río deje de estar revuelto". Ese es el más alto fin del Derecho: poner orden en el caos y generar convivencia, tranquilidad, seguridad (jurídica y de todo tipo) $y$, en definitiva, paz en sentido positivo.

\footnotetext{
${ }^{15}$ Esta es la idea que nos pretende transmitir Carnelutti, F. 2010. Cómo nace el Derecho. Marcial Pons. Bogotá.

${ }^{16}$ Carnelutti. Op. Cit. Pág. 32.
} 
En contraposición, en el pensamiento puramente económico, donde reina el depredador, no hay paz. Por eso el Derecho debe estar siempre bien engrasado, afinado y actualizado: para que sea la justicia la que reine por convicción y por convención.

Como es de conocimiento general, el Derecho no es sólo un mecanismo de defensa pasivo, sino todo lo contrario, es un mecanismo de defensa activo que se actualiza y renueva a través de los medios y procedimientos que implementan tanto el legislador como los operadores de todo el cuerpo normativo. Gracias a su continuo reforzamiento y actualización se van neutralizando, con más o menos rapidez pero con eficacia, la actuación de cualquier Giges de Lidia que crea haber encontrado el anillo que le permita cometer injusticias sin ser visto.

De manera que si algo desincentiva a quien está al otro lado de la paz y de la convivencia, es saber que disponemos de gafas que permiten ver los trucos y que disponemos de unos mecanismos de defensa sólidos que impedirá competentemente que el transgresor se deje guiar por sus instintos.

Sería una ingenuidad pensar que la historia del anillo de Giges acabó en la República de Platón, o que es una historia más de ciencia ficción. Es indiscutible que el profesional del Derecho (juez, fiscal, abogado o funcionario) desarrolla su actividad diaria en unos contextos fácticos en los que la vulneración del Derecho y de los derechos de los demás no sólo se hace cotidiana, sino que cada día presenta nuevas formas capaces de asombrar al más incrédulo. En consecuencia, sólo puede pensarse que los años de experiencia proporcionan a estos juristas unas enseñanzas, que se emplean en perfeccionar su eficacia profesional, para erradicar conductas conflictivas, para eludir la expansión de ese modus vivendi o para desincentivar modelos de vida equivocados. En definitiva, para contribuir a lograr el mundo mejor que todos merecemos.

Trabajar en esos escenarios pestilentes, conocerlos y dominarlos, permite descubrir zonas de sombras que no han sido convenientemente iluminadas por el legislador; lleva a encontrar senderos ocultos que permiten eludir los controles del Estado de Derecho y localizar gateras que conducen impunemente hasta los extramuros de la norma. Pues bien, todos esos conocimientos y experiencias sólo pueden y deben usarse para taponar y neutralizar esas zonas sensibles, indefensas e inseguras.

Es fácil caer en la tentación de ocultar ese punto secreto donde una persona se vuelve invulnerable o invisible a la ley; ese sitio íntimo donde el bueno puede permitirse el lujo de ser malo sin que nadie lo sepa o sin que nadie pueda probarlo, es decir, sin que le acarree consecuencias jurídicas y sociales. Estos son "los anillos de Giges" que aparecen continuamente en la sociedad.

Para ello, el Derecho evita o resuelve, en su caso, la agresión, la apropiación o la humillación, pero, consciente de los límites, no puede evitar todas las conductas humillantes, agresivas o apropiadoras, porque el Derecho puede ser utilizado hábilmente por quienes lo conocen para estirarlo en el propio beneficio, sin que sea quebrantado. Sólo una vivencia plena del valor del respeto y de la justicia, permite que no se pueda humillar, aún cuando el agresor sabe que no podría acreditarse su conducta malévola o que su acción no se ajusta a la tipificación que recoge la norma.

Por consiguiente, ya sea por convicción ya sea por convención, es claro que el jurista debe tener mentalidad de justicia y estar preparado para reaccionar ante la injusticia. Quien invoca y cultiva los valores, no coqueteará con la venganza, con la violencia o con la corrupción. En definitiva, no aspirará a lo que uno no es, ni a lo que no es de uno. 
Y en este sentido, para que no se actúe por conveniencia y hacer lo que la conciencia dicte, es preciso hacer lo que hay que hacer, cuando hay que hacerlo. Esto es: "aprender a ser". Aprender y enseñar con motivación y sin miedos; con libertad y dignidad; con vocación de servicio; buscando la reciprocidad indirecta y barriendo restos y rastros de desigualdad.

¿Quién será el responsable de lograr todo esto en las aulas de Derecho? ¿Sólo el profesor o profesora de Filosofía del Derecho?

¿Es suficiente con que el estudiante de la Facultad de Derecho sepa a la perfección los textos legales, recite sin pestañear la doctrina y sepa hacer magníficos escritos? ¿No será eso más propio de una academia de opositores?

La práctica de los principios y valores éticos -el "saber ser"- no sólo proporciona los efectos directos que hemos tratado de explicar, sino que también produce efectos indirectos no menos importantes. Existen competencias que se adquieren por derivación de esos valores principales, como es la capacidad de trabajar en equipo, lo cual, es una necesidad técnica y organizativa y supone el aglutinante ineludible para que la empresa, el centro u organización en el que el profesional presta sus servicios, pueda alcanzar objetivos comunes. Así, el trabajo en equipo es la realización del bien común y esto se logra con cooperación y respeto. El equipo y no la conducta individual será lo que haga próspero el desarrollo.

En cualquier caso, el bien común será el fruto de que todos conocemos el sentido del respeto, la responsabilidad, la honestidad, el patriotismo o la justicia. No basta con que alguno de los miembros de la sociedad haya estudiado a los grandes pensadores y haya delimitado con nitidez los conceptos ético-morales. Si uno sólo de los ciudadanos no sabe lo que es el respeto, todos lo sufrimos. Y no deja de ser preocupante que esta idea básica ya existiera en Platón ${ }^{17}$ y todavía no esté lo suficientemente enraizada.

De la misma manera ocurre con el tan traído y llevado fenómeno de la corrupción. No sólo a aquellos que ejercen potestades y cargos públicos les afecta la integridad, la imparcialidad, el decoro o la decencia, sino que todos y cada uno de nosotros debemos estar sanos de la larva de la corrupción. Aquellos con más pulcritud y transparencia (evidentemente).

Esto puede ser una utopía, pero, a veces, aquellas referencias ideales y difíciles de alcanzar, son las que nos dan fuerzas para seguir caminando. Todo menos entregarnos a que, finalmente, esa epidemia acabe torpedeando la seguridad jurídica de todos. La

${ }^{17}$ Zeus, entonces, temió que sucumbiera toda nuestra raza, y envió a Hermes que trajera a los hombres el sentido moral y la justicia, para que hubiera orden en las ciudades y ligaduras acordes de amistad. Le preguntó, entonces, Hermes a Zeus de qué modo daría el sentido moral y la justicia a los hombres: “¿Las reparto como están repartidos los conocimientos? Están repartidos así: uno sólo que domine la medicina vale para muchos particulares, y lo mismo los otros profesionales. ¿También ahora la justicia y el sentido moral los infundiré así a los humanos o los reparto a todos?". "A todos, dijo Zeus, y que todos sean partícipes. Pues no habría ciudades, si sólo algunos de ellos participaran, como de los otros conocimientos. Además, impón una ley de mi parte: que al incapaz de participar del honor y la justicia lo eliminen como a una enfermedad de la ciudad". Platón. 1993. Diálogos. Protágoras. Madrid. Gredos. Pág. 526. 
corrupción es un veneno letal para la igualdad de oportunidades. Cuando alguien satisface necesidades con recursos que no les pertenece, cuando alguien accede a algo que no le corresponde en igualdad de armas con los concurrentes, no hay justicia y no puede hablarse de igualdad de oportunidades. Quien bordea o burla la ley o las normas de control para satisfacer una necesidad propia, está infectado por el mal de la corrupción y participa de una mentalidad económica y no justa.

Independientemente de la cuantía y la trascendencia de los hechos, de la repercusión que tenga sobre el bien común o sobre terceras personas, si alguien con mérito, capacidad y circunstancias legítimas no puede acceder a lo que en justicia le corresponde, porque otra persona cuyo perfil no reúne esos criterios, lo ha conseguido mediante una actuación corrupta, la igualdad de oportunidades, como principio, se desmorona.

Por otra parte, si no se ha accedido a un empleo o cargo público con absoluta limpieza y transparencia (sobre la base de los principios que la Constitución y el resto del ordenamiento jurídico establece para ello) es más difícil esperar que ese empleado público responda a un patrón moral o a una conducta ética. Todo ello sin olvidar que, en un futuro más o menos próximo, quienes formen parte de los tribunales de selección, organicen los procesos selectivos, resuelvan recursos, gestionen recursos humanos, otorguen ayudas o subvenciones, etc., serán los juristas que nosotros formamos hoy.

En consecuencia, debemos adquirir el vértigo de la conciencia de que la prevención, la protección y la corrección de las conductas corruptas del futuro estarán en las manos de quienes ocupan los pupitres que tenemos frente a nosotros. Ese vértigo nos debe hacer conscientes, cada día, de las finalidades que pretenden las competencias generales, es decir, el "aprender a ser".

\section{4.- Conclusiones.}

La autonomía universitaria y la siempre respetada libertad de cátedra no impide, ni puede impedirnos, cuidar aspectos tan importantes, neutros y significativos en la formación integral del estudiante, como los que se han tratado de analizar. Es obvio que hay un objetivo que es la instrucción técnica y práctica del profesional del Derecho, pero también es preciso atender a formar el carácter del o de la jurista. La formación recibida debe ofrecer las herramientas intelectuales que permitan limpiar de corruptibilidad el actuar humano desde el convencimiento pleno de que debemos ajustar nuestro actuar a una vida buena.

Si todo cuanto se ha reflexionado nos conduce a pensar que existe la necesidad de "enseñar a ser", es lógico que exista una evaluación que acredite el "saber ser". No sólo una calificación, sino que el estudiante debe probar que ha interiorizado cuanto se ha dicho $\mathrm{y}$, sobre todo y por encima de todo, debe obtener las enseñanzas que la propia evaluación conlleva (como ocurre con cualquier otra materia).

El "saber ser" supone saber hacer frente a los problemas jurídicos, éticos y morales de antaño y de hoy. Así ocurre con los, siempre novedosos, problemas de la tecnología y de la comunicación. Esta revolución tecnológica, que nos atropella con vehemencia, a la vez que sentimos la necesidad imperiosa de subirnos a ella, reclama una atención constante para que todas estas exigencias y necesidades deban conciliarse con el más absoluto respeto al Derecho y a los derechos y libertades de los ciudadanos. Lo que está bien está bien aunque no lo hagamos nadie y lo que está mal está mal aunque todo el mundo lo haga. 
Las redes sociales no pueden volver blanco lo que es negro ni viceversa, por muchos "me gusta" o "retuis" que acumule. No pueden servir para obtener la razón cuando le ha sido denegada en los órganos legítimos del Estado. No puede servir para faltar el respeto a la persona por muy gracioso que sea. No puede sacralizarse una libertad (la de expresión) en perjuicio del resto de las libertades y de la dignidad de la persona. Esto está necesitado de investigación pero, sobre todo de docencia para su prevención, lo cual se hace más necesaria e intensa, si cabe, en las aulas de Derecho.

Por lo tanto, no es suficiente instruirse en las sapiencias jurídicas: "no basta reunir al Homo sapiens y el Homo faber, es preciso además, que se sienta en armonía con los demás y consigo mismo: Homo concors" "18; que mantenga la coherencia entre el decir y el hacer; que exista un equilibrio entre los sentimientos y la razón; que utilice con maestría la inteligencia, la lógica, la argumentación y el juicio ponderado y que defienda sus principios sin estar sometido a lo políticamente correcto.

En definitiva, alguien que no sólo se ha dotado a si mismo de unos buenos sistemas de navegación para pilotar su propia vida, sino que nos sirva de referencia para cuando nosotros "no veamos". Ésta es la dimensión personal (subjetiva) del cultivo de los valores, pero no son menos trascendentes sus resultados sociales.

Se preguntaba el profesor Sabater: ¿Y cómo puede instruirse a alguien en conocimientos científicos sin inculcarle respeto por valores tan humanos como la verdad, la exactitud o la curiosidad? ¿Puede alguien aprender las técnicas o las artes sin formarse a la vez en lo que la convivencia social supone y en lo que los hombres anhelan o temen ${ }^{19}$

Podemos consolarnos (o autoanestesiarnos) pensando que la sociedad ya no necesita los valores, que existe una crisis de valores, que los valores se han multiplicado y han mutado o que éstos no están perfectamente definidos, pero no podemos obviar que el comportamiento humano debe ser orientado hacia el bien común, la convivencia y el respeto. Desde esa base, nos atrevemos a contestar a las preguntas anteriores, diciendo que no es posible.

Si nuestro propósito docente es que nuestros egresados vivan armónicamente con ellos mismos y con los demás, en cooperación y no en competencia (homo concors), pensando en ellos, pero también contribuyendo al progreso social y al desarrollo humano, deben adquirir el significado personal y social del valor. Los nuevos profesionales deben ser conscientes de que esos valores no se alcanzarán mediante la obtención de un certificado académico en la secretaría de un centro o facultad, sino que el valor cuesta crearlo, cultivarlo y continuamente habrá que mantenerlo, porque hace crecer a la persona, le otorga una dimensión admirada (valorada) por los demás y la acerca al perfil de persona buena.

Así será, como decíamos al inicio de estas reflexiones, como estos hombres y mujeres, que cada año adquieren su titulación universitaria, abordarán el futuro.

Por cierto, aunque el lector ya lo habrá adivinado, se nos olvidaba recordar que esos párrafos iniciales que dábamos por publicados, están extraídos del Discurso de la Historia, pronunciado el 13 de julio de 1932 por Paul Valéry en el Liceo.

Continuaba el escritor francés diciéndole a los alumnos que: "Tienen, entonces, que armar su espíritu; lo cual no quiere decir baste con instruirse”.

\footnotetext{
${ }^{18}$ Informe de Faure, E. Op. Cit. Pág. 45.

${ }^{19}$ Sabater. Op. Cit. Pág. 23.
} 


\section{Bibliografía.}

ANECA. 2013. Guía de apoyo para la redacción, puesta en práctica y evaluación de los resultados del aprendizaje. Madrid.

Disponible en: http://www.aneca.es/Documentos-y-publicaciones/Otras-guias-ydocumentos-de-evaluacion

Arana Ercilla, M.-Batista Tejeda, N. 1999. "La educación en valores: una propuesta pedagógica para la formación profesional". Revista Pedagogía Universitaria Vol. 4, Número 3.

Carnelutti, F. 2010. Cómo nace el Derecho. Marcial Pons. Bogotá.

Cortina. A. 2000. Ética mínima. $6^{\circ}$ ed. Madrid. Tecnos. Disponible también en https://es.slideshare.net/JennyJimenez1/cortina-adela-eticaminima-16493201.

Delors, J y otros.VVAA.1996. La educación encierra un tesoro. Madrid, Santillana/UNESCO.

Faure, E. y otros. (Versión española de Paredes de Castro, C.)1973. Aprender a ser. La educación del futuro. Madrid. Alianza editorial.

Navarrete, R. 1993. El aprendizaje de la serenidad.6ª Ed. Madrid. San Pablo.

Pérez Lledó. J. A. 2007. “Teoría y práctica en la enseñanza del Derecho”. Academia: revista sobre enseñanza del derecho de Buenos Aires, Año 5, Número 9.

Sabater, F. 1997. El valor de educar. Barcelona. Ariel.

Schulz, K. 2015. En defensa del error. Madrid. Siruela.

Sennett. R. 2003. El respeto. Sobre la dignidad del hombre en un mundo de desigualdad. Barcelona. Anagrama.

VVAA. Instituto de Ciencias de la Educación. 2008. Competencias genéricas y transversales de los titulados universitarios. Universidad de Zaragoza. Disponible en: http://www.unizar.es/ice/images/stories/publicacionesICE/Col.\%20Documentos\%2008. pdf.

Versión en español revisada por Raffaella Pagani. 2009. Una introducción a Tuning Educational Structures in Europe; la contribución de las universidades al proceso de Bolonia. Bilbao. Publicaciones de la Universidad de Deusto. 